\title{
PerCursos
}

\section{O imaginário político-ambiental brasileiro na dobra do regime colonial capitalístico}

\section{Resumo}

O presente artigo teve como objetivo central cartografar os discursos que orientaram as formas de acumulação do capital durante o Brasil colônia, bem como os discursos que orientam a atual fase do capitalismo, em sua dobra colonial-capitalística. Para satisfazer tal objetivo, utilizou-se do método cartográfico. Nesse ínterim, resgataram-se escritos que documentam o trato com a natureza durante o Brasil colônia, intentando demonstrar que o discurso ensejado neste período retorna, sob as bases políticas e econômicas do inconsciente colonial-capitalístico do presente, sob a chancela da crise econômica. Para cartografar as bases desse segundo momento histórico do imaginário político-ambiental brasileiro, integram os resultados e análises desse ensaio os discursos emitidos por chefes de estado dos últimos mandatos (governo Dilma/Temer/Bolsonaro), veiculados nas instâncias midiáticas. $\mathrm{Na}$ análise de tais dados buscou-se demonstrar a construção do que fora chamado de dispositivo negacionista.

Palavras-chave: Dispositivo negacionista. Capital. Crise econômica.

\author{
Adalberto Ferdnando Inocêncio \\ Doutor em Ensino de Ciências \\ pela UEL. Professor da \\ Universidade Estadual de \\ Maringá - UEM. \\ Brasil \\ afinocencio88@gmail.com
}

\footnotetext{
Para citar este artigo:

INOCÊNCIO, Adalberto Ferdnando. O imaginário político-ambiental brasileiro na dobra do regime colonial capitalístico. PerCursos, Florianópolis, v. 21, n.47, p. 197 - 226, set./dez. 2020.
}

DOI: $10.5965 / 1984724621472020197$

http://dx.doi.org/10.5965/1984724621472020197 


\title{
The brazilian political- environmental imaginary in the bend of the capitalism colonial regime
}

\begin{abstract}
The main objective of this article is to map the speeches that guided the forms of capital accumulation during colonial Brazil, as well as the speeches that guide the current phase of capitalism, in its colonial-capitalistic fold. To satisfy this objective, the cartographic method was used. In the meantime, writings that document the dealings with nature during colonial Brazil were rescued, intending to demonstrate that the speech created in this period returns, under the political and economic bases of the present colonial-capitalistic unconscious, under the seal of the economic crisis. To map the bases of this second historical moment in the Brazilian politicalenvironmental imaginary, the results and analyses of this essay integrate the speeches issued by heads of state from the last mandates (Dilma/Temer/Bolsonaro governments), broadcast in the media. In the analysis of such data, we sought to demonstrate the construction of what had been called a negationist device.
\end{abstract}

Keywords: Negacionist dispositive. Capital. Economic crisis. 


\section{Introdução}

O presente artigo é um recorte analítico decorrente de uma tese de doutoramento que pretendeu investigar de quais maneiras a proliferação discursiva da crise ambiental, que emergiu nas últimas décadas, se relaciona com a construção das subjetividades no tempo presente. No recorte aqui selecionado apresentam-se e discutem-se as construções discursivas acerca do imaginário político-ambiental brasileiro, entendidas como decorrentes da ação de dispositivos que estão em vigor.

A hipótese traçada na investigação mais ampla foi a de que a atual forma de depredação objetiva que se percebe na natureza física que, no intercurso da modernidade passa a receber a designação de recurso natural, está imanente a uma depredação subjetiva, capturada pela atual dobra do regime colonial capitalístico ou cafetinístico, na conceituação dada por Rolnik (2018). Para entender essa atual forma de depredação, contudo, se faz necessária uma digressão aos modos de se relacionar com a natureza desde o desdobramento inaugural do Brasil colônia, uma vez que o discurso ensejado neste período retorna, sob outras bases políticas e econômicas, na sociedade brasileira do presente, desta vez, sob a chancela da crise econômica, o que o situa não somente no entrecruzamento do capital financeirizado global, mas arrasta consigo uma crise climática sem precedentes (LATOUR, 2020).

Nesse sentido, o objetivo desta investigação foi o de cartografar tanto os discursos que orientaram as formas de acumulação do capital durante o Brasil colônia, como os que orientam a atual fase do capitalismo, em sua dobra colonial-capitalística. Tal incursão visibiliza o fato de que aquilo que se considera como problemas ambientais na atual conjuntura esteja imanente à uma economia política, regida por uma discursividade histórica mais ampla que atina para a acumulação primitiva de capital (mesmo que sob outras bases) como uma rota incontornável.

As noções de discurso e dispositivo, adotadas nesta investigação, são do filósofo francês Michel Foucault. Nesta perspectiva, discurso diz respeito a uma prática social (FOUCAULT, 2013). Em tal acepção, o discurso não é apenas um elemento restrito à representação do mundo por meio da linguagem, mas sim, uma prática. Ele produz 
relações. Além disso, há uma ordem do discurso, isso é, uma lógica segundo a qual “[...] em toda sociedade a produção do discurso é ao mesmo tempo controlada, selecionada, organizada e redistribuída por certo número de procedimentos que têm por função conjurar poderes e perigos" (FOUCAULT, 2012, p. 8), o que significa dizer que a produção discursiva é imanente aos interesses daqueles que a produzem e os fazem circular na economia política de uma dada sociedade. Em outras palavras: "[...] o discurso ultrapassa a simples referência a coisas" (FISCHER, 2001, p. 200).

Pari passu, o conceito de dispositivo pode ser entendido como "um conjunto decididamente heterogêneo que engloba discursos, instituições, organizações arquitetônicas, decisões regulamentares, leis, medidas administrativas, enunciados científicos, proposições filosóficas, morais, filantrópicas” (FOUCAULT, 2015, p. 364), ou, ainda, "um tipo de formação que, em um determinado momento histórico, teve como função principal responder a uma urgência [...] tem, portanto, uma função estratégica dominante" (FOUCAULT, 2015, p. 365). Nesse sentido, o dispositivo alude ao uso de um conceito-instrumental que atua para convencer ou, na leitura foucaultiana, para a naturalização de certos processos sociais que não são, em si, naturais. Teoricamente, o dispositivo "dá um passo além" do discurso, uma vez que integra, em sua definição, os elementos discursivos e não discursivos, e permite a compreensão de que determinadas práticas sociais são historicamente orientadas a certos interesses específicos.

Para efeito da analítica deste trabalho, admite-se que cada elemento cartografado nesta investigação esteja entretecido nas malhas de um dispositivo, tanto em elementos documentais, legais, como na admissão de órgãos específicos, institucionalizados e, portanto, capazes de articular modos de vidas específicos de se relacionar com a natureza no âmbito da população. Desse modo, a acumulação do capital no Brasil colônia fora instigada por seus próprios dispositivos; da mesma forma que o regime colonial capitalístico é orientado em outra trama. São também dispositivos de Estado, ou de Agenda Nacional, todo o conjunto discursivo, manifesto nas formas de entrevistas e declarações públicas anunciadas por chefes de Estado que, apesar de não levarem a mesma chancela de um documento oficial, mantêm o mesmo efeito: o de "conduzir condutas". 
Como conceitos operadores desta investigação, tanto o discurso como o dispositivo auxiliaram o entendimento de que os modos de se relacionar com a natureza são (a) diferentes em cada sociedade (cada sociedade tem seu conjunto de discursos e dispositivos próprios); (b) inconstantes ao longo do tempo no interior de uma determinada sociedade (uma vez que está imanente a relações de poder de determinadas redes de interesses); além disso, (c) a preocupação com a rarefação dos recursos é um elemento relativamente novo na história brasileira. Acerca desta última categorização, importa sublinhar que, da mesma forma que existe uma preocupação voltada aos recursos naturais, proveniente da investida dos movimentos ambientalistas em seu caráter heterogêneo, há uma "captura" desse mesmo discurso orientada pela lógica do capital (MORENO, 2016), haja vista que a nova dobra do regime capitalista se configura pelo descrédito ao poder de persuasão das ciências e de ativistas ambientais - o que leva à posições negacionistas ${ }^{1}$ diante de fatos como, por exemplo, o aquecimento global mesmo porque a adesão de plataformas e agendas decorrentes das negociações climáticas não é do interesse de alguns chefes de Estado (LATOUR, 2020).

Em vez de esquadrinhar um percurso caracterizado por fases nítidas que representassem contornos acentuados de começo, meio e fim, adotou-se a cartografia (PASSOS; KASTRUP; ESCÓSSIA, 2015) como abordagem metodológica. O conceito foucaultiano de discurso funcionou como operador na escolha das materialidades discursivas encontradas, permitindo analisá-las em suas recorrências e descontinuidades.

\section{Breve histórico da acumulação sob a lógica colonial no Brasil}

A natureza brasileira, sob o viés do Brasil colonial, fora amplamente documentada numa historiografia que ganhou o corpo de várias obras importantes. Em Raízes do Brasil, Sérgio Buarque de Holanda (1981, p. 165) observou que no cenário brasileiro as relações com a natureza já assumiam um caráter alienante, uma vez que estiveram marcadas por

\footnotetext{
1 Posições negacionista não são, necessariamente, imanentes à nova configuração do capital global. A diferença é, segundo Latour (2020), que agora existem investimentos milionários de alguns setores da comunicação trabalhando numa sistemática operação para a negação da existência de mutações climáticas, simplesmente negando que elas existam, quando não abrandando suas consequências sob o eufemismo de "Novo Regime Climático".
} 
uma conduta de geração de "riqueza que custa ousadia, não riqueza que custa trabalho", caracterizada pela ausência do que ele nomeou por "vontade criadora" do colonizador.

Também Caio Prado Junior (1971) enfatizou a permanência do caráter predatório e perdulário da extração de riquezas da terra para satisfazer os interesses do capital. No que documentou esse autor, as longas áreas de vegetação nativa representariam o motivo de os trópicos terem sido atrativos para a "fria Europa". "A América Ihe poria à disposição, em tratos imensos, territórios que só esperavam a iniciativa e o esforço do homem" (PRADO JR, 1971, p. 22). Esse trecho é elucidativo quanto ao sentido da colonização: fornecer ao comércio exterior europeu gêneros tropicais e minerais considerados importantes para a época. Em sua análise não há qualquer evidência acerca da preocupação social atinente aos efeitos ambientais futuros, decorrentes de uma monocultura implementada com base na força de trabalho escravo. Apesar desta obra ter focado nos processos de povoamento e implementação da economia que caracterizaram o início da colonização, o autor sustenta que tais processos não foram totalmente substituídos no período de modernização que caracterizou o século XX do Brasil república.

As descrições acerca dos processos de acumulação no período do Brasil colonial não se restringiram às obras brasileiras. O historiador norte-americano Warren Dean (1996) destacou suas análises nas queimadas e nomadismos decorrentes da agricultura praticada no Brasil do século XIX por proprietários de terras, grandes e pequenos. $O$ imaginário desse período se assentava na concepção dos produtos naturais como "recursos transitórios", de modo que este indicasse ausência de preocupação com a preservação ou mesmo de reposição das condições de disponibilidade desses recursos. $O$ autor incluía no rol exploratório não apenas produtos extraídos das matas, como a madeira, a lenha, os cipós e o carvão, mas produtos minerais, como o ferro, a cal e a água. Complementa, ainda, que o fato de, no Brasil, a agroindústria, sobretudo cafeicultura e de cana-de-açúcar, ser a raiz da industrialização, o uso intensivo de lenha e carvão vegetal justificou o uso depauperado desses elementos, causando a supressão das florestas tropicais de Mata Atlântica na costa e centro-sul do país. 
Na análise histórica de Martinez (2006, p. 29, grifo nosso) a memória coletiva de todos esses séculos - historiografada nas escritas dos autores supracitados - contribuiu para uma idealização dos recursos encontrados nas terras brasileiras, isso é, a criação de um discurso que “[...] apresentou a natureza no Brasil como portadora de riquezas infinitas e inesgotáveis, dada a exuberância da vegetação, abundância da água, diversidade da fauna e da flora, fertilidade dos solos". Daí o interesse em resgatar essa memória discursiva, uma vez que ela orientou um discurso secular que continua tendo reverberações na sociedade brasileira hodierna. Em sentido foucaultiano reverberação diz respeito a uma condição para se referir às "coisas ditas uma vez e que se conservam", a discursos que "se dizem no correr dos dias e das trocas [...] são ditos, permanecem ditos [...]"(FOUCAULT, 2012, p. 21).

Contudo, a ideia da inesgotabilidade dos recursos teve contrapontos e também fora combatida historicamente. Em larga medida esse contraponto:

[...] derivou de um acúmulo de esforços empreendidos pelas ciências naturais, e que remontam aos tempos de colônia e do Império, fortemente marcados seja pelo fantasioso seja pelo utilitarismo econômico. Nesta perspectiva, ao longo do século XIX, ainda que difusas e esparsas, não faltaram manifestações de assombro e alertas para a mudança de comportamentos no aproveitamento dos recursos naturais no Brasil. Esta memória alimenta uma indagação recorrente, sobre como um país que dispõe de produtos naturais abundantes possui e reproduz incessantemente um quadro social historicamente maculado pela desigualdade social e a espoliação econômica [...] Assim, a História Ambiental no Brasil pode lançar luz sobre a racionalização dos interesses econômicos, contidos na mistificação do "progresso" [...], na "conquista" da terra e da natureza e outros mitos criados, cotidianamente, pela mídia, governos, empresas, movimentos ambientalistas, cientistas e acadêmicos em geral. (MARTINEZ, 2006, p. 29-30)

Nesse sentido, a narrativa de acumulação primitiva do capital, historiografada nas obras desses autores, é transicionada para uma nova fase, caracterizada nos efeitos das lutas promovidas pelos movimentos ambientalistas brasileiros, que se adensam na 
década de 1970 e passam a ser reconhecidos, na década seguinte, como novos movimentos sociais. No campo discursivo, essa fase aciona politicamente condições de existência que garantiram a criação de saberes e poderes voltados à preocupação ambiental. A década de 1990 é paradigmática com o Brasil sendo sede para a Eco-92 e com o evento que comemorou os quinhentos anos da América Latina, sediado na Espanha. Reigota (1999, p. 28) assinala que ambos os eventos serviram como ocasião, encampada por intelectuais latino-americanos, de "colocar em evidência o saque aos nossos recursos naturais e o etnocídio provocado pelas autodenominadas culturas superiores".

Reigota (2002) argumentará que tais condições de existência não foram simplesmente adotadas pela via dos movimentos sociais, mas, também (e significativamente) sob um viés moralizante, isso é, como normativas institucionais, principalmente decorrente de acordos econômicos estabelecidos pelo mercado globalizado. Nesse viés moral, o discurso proveniente dos movimentos sociais ambientalistas, que é heterogêneo por excelência (GUIMARÃES, 1998), sofre "capturas", "afunilando-se" em duas correntes, cujo posicionamento ideológico já se ancora nas discursividades do capital multinacional: a "alarmista" e a "técnico-administrativa" (REIGOTA, 2002).

A primeira esteve intimamente relacionada com a publicação do Relatório do Clube de Roma em 1968; e a segunda, complementando as bases da primeira, tem nas Nações Unidas e na Conferência Mundial sobre o Meio Ambiente Humano, conhecida como a Conferência de Estocolmo, em 1972, os seus principais referenciais. As vertentes "alarmista" e "técnico-administrativa", tiveram importância fundamental não só no debate teórico, mas também, e principalmente, "na implementação de políticas e projetos, sobretudo nos países do Terceiro Mundo"; de acordo com o mesmo autor, os programas de controle do crescimento demográfico na África e na América Latina e a expansão do parque industrial poluidor e a multinacional no Brasil e na Índia são os exemplos mais conhecidos (REIGOTA, 2002, p. 35). 
Na simplificação que caracteriza os movimentos “capturados” na lógica do capital, a corrente alarmista aparece como carro chefe do discurso dos países desenvolvidos que, lamentando o esgotamento dos recursos, viu nesse quadro uma situação perigosa e inerente ao seu modelo de desenvolvimento, ao mesmo tempo em que viam, contraditoriamente, como possibilidade o benefício de consumir os recursos presentes, ainda de forma abundante, nos países em desenvolvimento. No cenário geopolítico, tais vertentes contribuíram para uma transferência do problema, e não para uma solução.

Situação intrínseca ao claro interesse no "progresso" que colocava em evidência uma preocupação que não se voltava à questão ambiental, mas ao esgotamento de matéria-prima e agravante de problemas ambientais restritos a países desenvolvidos. Desse modo, a vertente técnico-administrativa proposta pelas nações industrializadas, caracterizou-se pela ideia de transferir e instalar indústrias com alto potencial poluidor nos países em vias de desenvolvimento.

Essa falsa ideia de que os ideais republicanos criariam condições favoráveis a preocupações em sentido ético à natureza no terceiro-mundo foi discutida por Gonçalves (2008), ao descrever a emergência dos movimentos sociais ecologistas na realidade brasileira. Retomando o quadro político-cultural particular, no qual emerge no Brasil, o movimento ecológico, a década de 1970 assinala o regime de ditadura militar em vigência, aludindo a uma barreira ideológica para a ideia desses movimentos que incitavam mudança nos padrões, em especial o ambientalista, uma vez que não era característica das elites dominantes uma preocupação com a preservação da natureza. Exemplos claros da negação aos movimentos foram os episódios em que houve total repúdio às pautas apresentadas pelos então movimentos sindicalistas e estudantis desse período. O país atravessava um discurso desenvolvimentista: "Tecnocratas brasileiros, participantes de seminários e colóquios internacionais, declaram que a 'pior poluição é a da miséria' e tentam atrair os capitais estrangeiros para o país" (GONÇALVES, 2008, p. 15).

Diante do cenário internacional, no entanto, a retórica ambientalista ganhou, cada vez mais dimensão, impondo às instituições financeiras tais exigências. É nesse sentido que o Brasil passou a fazer parte das políticas globais reestruturadas, contudo, a partir do capital e pelo capital, de modo que, na prática, não sustentavam como interesse uma 
preocupação efetiva com essas questões, caracterizando-se muito mais por uma política “mascarada" por retóricas voltadas a fortificar seu pertencimento com o comércio internacional, ou seja, interesses de fundo econômicos apenas (reforçando o caráter dependente do capitalismo nacional).

Assim, antes que houvesse enraizado no país um movimento ecológico, o Estado criou diversas instituições para gerir o meio ambiente, a fim de que os ansiados investimentos pudessem aqui aportar. Diga-se de passagem que estas instituições incluem, nos seus quadros, técnicos que se preocupam efetivamente com as condições de vida, porém a lógica destas instituições é determinada pela política global de atração de investimentos e não pelo valor intrínseco da questão ambiental. (GONÇALVES, 2008, p. 15)

Apesar do caráter denuncista colocar em evidência a lógica dessas instituições, não se pode esmorecer a fatalismos, isso é, o conjunto dessas instituições cumpriram um papel produtivo - ainda que voltado a interesses da política global de atração de investimentos - na criação de saberes, como as ciências ambientais, que propuseram derivações nas grandes áreas de saber já existentes - como a educação ambiental, o direito ambiental, a gestão ambiental, para ficar nesses exemplos, - e poderes - como os papéis de monitoramento e vigilância das áreas de proteção ambiental, consagrados num Sistema Nacional de Unidades de Conservação (SNUC), das águas (Agência Nacional das Águas) e das espécies animais, vegetais e dos minerais (Instituto Brasileiro do Meio Ambiente e dos Recursos Naturais Renováveis), para ficar nesses exemplos.

As exemplificações trazidas anteriormente se caracterizam por alguns autores como ambientalização das lutas sociais (ACSELRAD, 2010; BRÜGGER, 2003). Essa noção de ambientalização vem acompanhada de um duplo movimento: ao mesmo tempo que garante a incorporação das questões ambientais na luta por justiça social (justiça ambiental), setores privados, como as empresas, "ambientalizam" seus discursos, de forma que "se blindam" a controles externos, ao que Moreno (2016) se refere por “esverdeamento da economia". Nessa lógica, tais setores mais transferem a 
responsabilização para a população, pensada como consumidora - já que os produtos, agora, também dizem respeito às escolhas mais ou menos "ecológicas" -, ao passo que atenuam a responsabilidade do sistema de produção, que nada muda em suas estruturas, em suas bases de produção ou na forma de acumulação do capital. Desse modo, no intercurso dessa "maquiagem verde", como chama Brügger (2003), os avanços são sempre parciais, uma vez que essa ambientalização opera pela lógica do capital. Ambas as análises estabelecem diálogo com o conceito de cafetinagem, discutido por Rolnik (2018) e apresentados a seguir, pois este se caracteriza pela captura da ambientalização promulgada pelos movimentos, em sentido objetivo e subjetivo.

Assim, o imaginário brasileiro incorporou o discurso dúbio e ressignificado dos movimentos ambientalistas sob essa vertente da ambientalização das lutas sociais. $\mathrm{Na}$ década de 1990, momento em que tais ideais já haviam reverberado nas instâncias midiáticas, existiu a crença generalizada sobre o papel educacional e a criação de outras instâncias para a superação de inúmeros problemas ambientais. Esses dados foram demonstrados na pesquisa publicada com o título de $O$ que o brasileiro pensa sobre a ecologia, na qual é afirmada a representação de que "a educação é a grande saída consensual e entusiasticamente defendida por todos" (CRESPO; LEITÃO, 1993, p. 172).

Tal posição reaparece em 1997, pela pesquisa posteriormente publicada com o título O que o brasileiro pensa do meio ambiente, do desenvolvimento e da sustentabilidade, revelando, dentre outros dados, que "para 95\% dos brasileiros, a Educação Ambiental deve ser obrigatória nas escolas" e que o desenvolvimento sustentável seria uma possibilidade viável para o cenário brasileiro (CRESPO; LEITÃO, 1993 p. 17).

Por fim, em 2012, ano em que a edição da Rio +20 fora sediada no Brasil, uma pesquisa similar é encampada novamente por Crespo (BRASIL, 2012, p. 17), na qual a análise da amostra investigada revelou que $43 \%$ dos brasileiros declararam se sentir orgulhosos com o país, sendo o motivo desse orgulho a concepção da "natureza vista como rica, bela e abundante"; destes, $28 \%$ "citaram belezas naturais e paisagísticas quando falaram que se orgulham". 
Interessa citar os dados dessas pesquisas de opinião pública uma vez que reafirmam, tantas décadas após a suposta implementação de regimes republicanos e progressistas, concepções de uma natureza abundante e cênica, construção discursiva vigorada desde o Brasil colônia. Ainda que a última pesquisa citada reconheça as contradições atuais das políticas ambientais (e da política partidária, de forma mais ampla) (demonstrado pelo índice de $48 \%$ de brasileiros que se declararam insatisfeitos com as gestões governamentais do então primeiro mandato do governo Dilma Rousseff), prevalece um número considerável no imaginário brasileiro daqueles que veem o país caracterizado pela abundância natural.

\section{A cartografia como método investigativo}

Tendo identificado o problema de pesquisa que guiaria as análises mais amplas da investigação que compôs este ensaio, não fora esquadrinhado um percurso metodológico caracterizado nitidamente por fases que representassem contornos acentuados de começo, meio e fim. Em vez de regras e protocolos, apostou-se que o método cartográfico está mais próximo da composição de pistas² que, em conjunto, contribuirão para a construção do dispositivo que será analisado.

Buscando um método que estivesse em sintonia com o caráter processual de investigação, encontrou-se em Passos, Kastrup e Escóssia (2015) elementos imprescindíveis para a construção do caminho metodológico. Novamente, os autores não trazem uma série de a prioris, e optam por oferecer um instrumental que mais se assemelha ao que Foucault falara uma vez sobre sua obra funcionar como uma caixa de ferramentas. No método cartográfico "o primado do caminhar que traça, no percurso, suas metas" (PASSOS; BARROS, 2015, p. 17), isto é, não se trata de caminhar para alcançar

\footnotetext{
2 De acordo com Passos, Kastrup e Escóssia (2015), no delineamento do método da cartografia/cartográfico, como pesquisa de intervenção e produção de subjetividade, há pistas a serem seguidas, de modo que não há uma sequência linear de passos, mas escolhas e usos que se fazem no acompanhamento de um processo orientado pela atenção, necessidade e, até, sensibilidade do cartógrafo. Indica-se que não se usufruiu de todos os textos desta mesma coletânea, uma vez que há direcionamentos que se inclinam para a área de psicologia clínica, foco que não interessou a esta investigação.
} 
as metas prefixadas do metá-hódos (metá - reflexão, raciocínio, verdade; hódos caminho, direção), por isso, faz mais sentido a inversão hódos-metá.

De forma mais livre, apresentam-se as pistas conforme sentiu-se a necessidade de cada uma durante o percurso da investigação, tomando o cuidado de explicitar de que modos estas se encaixaram em cada uma de suas fases. Nesse ponto, importa mencionar que no âmbito da investigação geral da tese, adotou-se como premissa que os efeitos dos movimentos ambientalistas produzem efeitos diferentes nos Estados-nação. Em países do norte, orientam-se por condutas mais rígidas, denominadas, no estudo mais amplo, por ecologias policialescas, que perscrutam as condutas das populações humanas.

Na América Latina e no Brasil, mais especificamente, identifica-se um discurso de caráter retórico: existem as leis e disposições que absorveram as recomendações dos movimentos ambientalistas, mas, por assumirem um direcionamento moral, que advém de uma exigência dos mercados globais, prevalecem os interesses entreguistas dos recursos naturais. Os discursos reverberados por chefes de Estado que evidenciam um negacionismo da questão ambiental (necessário, aliás, para que exista uma posição entreguista) são os resultados e discussão apresentados neste recorte e o caráter negacionista acentuado na seleção dos discursos que compuseram o corpus analítico aqui apresentado.

Deleuze e Guattari (2011, p. 30) definem a cartografia como um olhar específico por meio do qual não apenas se acompanha, mas se constrói um mapa: "O mapa é aberto, é conectável em todas as suas dimensões, desmontável, reversível, suscetível de receber modificações constantemente [...] Um mapa é uma questão de performance". Nesse âmbito, cartografar está menos próximo de representar um objeto (que estaria pronto e foi simplesmente deslocado de um lugar para outro) do que acompanhar um processo que pode ter múltiplas entradas.

Acompanhar um processo está mais próximo ao movimento cartográfico, que escava os ditos e os saberes e os situa na posição histórica de sua condição de existência. Cartografar é, nesse sentido, reconhecer que não é porque algo está presente que, 
necessariamente, esteja visível: "[...] se trata de transformar para conhecer, e não de conhecer para transformar a realidade" (PASSOS; BARROS, 2015, p. 18).

Além disso, a cartografia não visa isolar o objeto de suas articulações e conexões com o mundo. Ao contrário, o objetivo da cartografia é “[...] justamente desenhar a rede de forças à qual o objeto ou fenômeno em questão se encontra conectado, dando conta de suas modulações e de seu movimento permanente", para isso "é preciso, num certo nível, se deixar levar por esse campo coletivo de forças" (BARROS; KASTRUP, 2015, p. 57).

A produção do corpus analítico decorreu, então, de um intenso processo de procura e imersão nos textos encontrados, em seu complexo conteúdo discursivo. Os autores indicam, ainda, que o funcionamento da atenção no trabalho do cartógrafo é orientado por um tipo de bússola. Na série de textos encontrados, selecionaram-se aqueles encontrados nos dispositivos midiáticos cujos discursos aludem à construção de um dispositivo negacionista3 ${ }^{3}$, conceito criado nessa investigação para designar o caráter primitivo de acumulação do capital num momento recente da história brasileira, caracterizado pela implementação de ideais republicanos e democráticos que, em princípio, não aludem a uma leitura objetificada da natureza.

\section{A nova dobra do regime colonial capitalístico: um retorno à reificação da} natureza

Em que consiste o atual regime colonial cafetinístico e de que modo ele interfere nos modos de se relacionar com a natureza nas sociedades hodiernas? Por inconsciente colonial-capitalístico ou cafetinístico, Rolnik (2018) conceberá o regime do capitalismo em sua versão contemporânea, portanto, financeirizada, neoliberal e globalitária, que começa a se formar mundialmente na guinada do século XIX ao XX e intensifica-se após a Primeira Guerra Mundial com a internacionalização dos capitais. Esse novo regime não se

\footnotetext{
3 Neste momento, é imprescindível anunciar que a acumulação primitiva na contemporaneidade não demanda um dispositivo negacionista por excelência. Existem, inclusive, formas de que isso ocorra com a supervalorização dos discursos ambientais e ambientalistas capitalizados, como é o caso das mudanças climáticas, que só foram levadas a sério ao serem transformadas em negócio (MORENO, 2016). Na nova dobra, contudo, argumenta-se que o "esverdeamento" da economia sequer é sustentado como slogan, transparecendo sua verdadeira face: o interesse nos lucros possibilitados pelo capital mundial.
} 
sustenta apenas com a acumulação do capital, mas com a cafetinagem da força vital ${ }^{4}, 0$ que provoca desestabilizações temporárias, sustentando sua onipotência no tempo presente. O que Rolnik (2018) chama de nova dobra é considerado por Moreno (2016) como "novo passo de acumulação".

Para que essa acumulação primitiva do capital não conduza à oposição por parte da população, uma das características de seu novo fascismo é a captura e o abuso da força vital (ROLNIK, 2018), que se caracteriza pela incessante investida de diversas instituições que operam na construção de mundos enfraquecidos em sua força de criação, esgotando os diversos campos do pensamento humano. Isso porque esse regime atua no âmbito micropolítico - às esferas da vida cotidiana, às singularidades próprias de cada um, individuais ou coletivas, às pluralidades que se expressam nos modos de se relacionar distanciadas das relações, em princípio, institucionalizadas e burocratizadas -, reduzindo possibilidades de pensamentos outros, movidos por movimentos que, das décadas de 1980 até os anos 2000, não cessaram de gerir novas formas de viver no plano dessa segmentaridade. O que está subjacente na mobilização desses conceitos é a ideia de que não haverá uma transformação das estruturas de governo sem a modificação da segmentaridade micropolítica de produção da subjetividade (ROLNIK, 2018).

Neste artigo, interessam as implicações dessa modalidade de inconsciente para pensar nos modos de se relacionar com a natureza. É ainda Rolnik (2018) quem estabelece essa chave de leitura, ao afirmar que uma das formas de atuação do inconsciente colonial-capitalístico nas nossas subjetividades é a de nos desviar de nossos destinos éticos, isso é, destinos concebidos como caminhos micropolíticos capazes de força de criação. "É a força vital de todos os elementos de que se compõem a biosfera que é por ele expropriada e corrompida: plantas, animais, humanos etc.”, além disso, “[...] é também cafetinado o ecossistema planetário, do qual depende a composição e manutenção da vida: a crosta terrestre, o ar, as águas" (ROLNIK, 2018, p. 104).

Assim, com a dupla extração, a do mais valor e a da força criativa, a ontologia das populações humanas que já transformava a natureza e, ao mesmo tempo, a si própria,

\footnotetext{
${ }^{4}$ Nas palavras de Rolnik (2018, p. 29) "não somos sufocados apenas pelo ar poluído das grandes indústrias, mas pelas partículas tóxicas do regime colonial-capitalístico”.
} 
numa relação mediada pelo trabalho, adquire novos estatutos a partir da dobra do regime colonial cafetinístico. Daí a razão de Moreno (2016) atribuir à "economia verde" o caráter despolitizador, já que em vez de contestar o sistema de acumulação, apenas incorporou a ele a retórica ambiental.

A natureza, transformada em recurso natural pelo viés lógico que orienta o progresso moderno e alvo das depredações e práticas de espoliação desde a instauração do sistema econômico capitalista e seu desenvolvimento, agora é lida sob o viés da ambientalização das lutas sociais, representando um contraditório agravante na atual fase do capital, fase em que os recursos localizados na periferia do capitalismo estão abertos à exportação.

Baseada nas ideias propostas por David Harvey, Fontes (2017) já anunciara que as formas de expropriação atual não se limitam a uma organização social "primitiva” (Brasil colônia), mas são integradas à lógica imanente de expansão do capital. A acumulação por expropriação, para Harvey, se daria no interior mesmo do processo de eliminação das conquistas dos direitos básicos, o que não sustenta a oposição capitalismo normalizado versus predatório, haja vista que decorreriam de uma mesma economia política (FONTES, 2017).

Nesta nova dobra, a "[...] associação entre neoliberalismo e as formas primitivas de acumulação do capital alimentou a mercantilização da natureza", de modo que ela se tornou, na atual conjuntura, um dos alvos do novo fascismo (COLETIVO CENTELHA, 2019, p. 74). Em termos políticos e históricos, é como se tudo o que fora erigido como preocupação ambiental na incorporação do discurso republicano da modernidade estivesse, agora, em sacrifício.

Bastou que a crise econômica ganhasse reverberação discursiva para que a acumulação primitiva retornasse à tona e se consagrasse como solução única para o tempo presente, processo que Sampaio Junior (2017) tem denominado "reversão colonial". Caracterizando-se pela progressiva perda de autonomia do Estado brasileiro dentro do sistema capitalista mundial “[...] O projeto do capital é transformar o Brasil numa megafeitoria moderna - uma economia de 'tipo colonial', voltada para o exterior, 
baseada na produção em grande escala, no sistema de monocultura, tendo como sustentáculo o latifúndio, a mão de obra barata e a depredação do meio ambiente" (SAMPAIO JUNIOR, 2017, p. 58-59). A reversão neocolonial tem como efeito de sua proposta de crescimento econômico com regressão das forças produtivas, um rebaixamento ao mínimo civilizador da sociedade.

Enquanto no século passado as crises eram um fenômeno incerto e sazonal na atuação do capital; na virada de milênio, o inconsciente colonial capitalístico incorpora as crises, e as utiliza como forma de governo das vidas (ROLNIK, 2018; COLETIVO CENTELHA, 2019). Agamben (2016 p. 352) teoriza que essa palavra seja vazia de sentido, uma vez que não é utilizada como um conceito universal, mas sim como "[...] palavras de ordem para impor e obter restrições e sacrifícios que, de outro modo, e com razão, as pessoas não gostariam de fazer; ou, ainda, crise, no fundo, hoje é uma palavra de ordem que significa apenas 'obedeça!”". Na América Latina, ou, de modo mais geral, “[...] em países de tradição autoritária, a crise é capaz de fazer reviver e de renovar histórias de mais longo curso, de desrespeito às leis, descrença nas instituições e que sinalizam saídas dogmáticas e que se apresentam como as “salvadoras da pátria” (SCHWARCZ, 2019, p. 232).

O discurso de crise, ensejado pela modalidade discursiva imanente ao Inconsciente colonial-cafetinístico, é manifesto, então, para minar o imaginário, de modo que a acumulação primitiva do capital, nesses arranjos sociais mais recentes, passa a ser entendida como bode expiatório e “única saída” possível para retirar o país da recessão (COLETIVO CENTELHA, 2019). Nas próximas seções, apresenta-se e discute-se a última peça componente do dispositivo negacionista, caracterizada pelas declarações dos chefes de Estado brasileiros nos últimos anos.

\section{A captura do imaginário macropolítico brasileiro quando cede à lógica colonial do capital}

Nesta seção, são apresentados os dispositivos de Estado ou de Agenda Nacional, cartografados num conjunto discursivo, manifesto nas formas de entrevistas e 
declarações públicas anunciadas pelos chefes de Estado em caráter oficial e não oficial5. Vale ressaltar que embora as medidas de agravamento dos problemas ambientais se acentuassem nos últimos anos, como já fora aludido anteriormente, não se considera que esse quadro político-ideológico seja elemento recente na história ambiental do Brasil (MARTINEZ, 2006), nem algo restrito a posições político-partidárias (ainda que estas interfiram na intensidade da exploração).

Basta resgatar posturas dos setores da esquerda a respeito do projeto de lei do Novo Código Florestal, relatado pelo deputado Aldo Rebelo (na ocasião, posicionado ao lado da ruralista Kátia Abreu), no então primeiro mandado da presidenta Dilma, que chegou a afirmar, em tom de denúncia, que o chamado movimento ambientalista internacional nada mais é, em sua essência geopolítica, que uma cabeça de ponte do imperialismo (TRIGUEIRO, 2015).

Também não deixa de ser emblemática a falta de imaginação das forças de Estado, como chama a atenção Danowski e Viveiros de Castro (2017) a respeito da declaração pública da própria presidenta Dilma Rousseff, feita pouco antes da Conferência Rio +20 (Conferência das Nações Unidas sobre Desenvolvimento Natural), em 2012, em resposta a ativistas ambientais contrários ao barramento dos rios amazônicos para construção de megacentrais hidrelétricas: "Ninguém numa conferência dessas também aceita, me desculpem, discutir a fantasia. Ela não tem espaço para a fantasia. Não estou falando da utopia, essa pode ter, estou falando da fantasia" (DOMINGOS; MOURA, 2012, s.p.). É interessante destacar que tal declaração é pronunciada no Fórum do Clima. Antes da declaração da presidenta neste Fórum, a representante das ONGs, Sílvia Alcântara, acusara o governo de promover um retrocesso na questão ambiental e que, medidas como o Pré-sal, levariam o Brasil a ocupar o terceiro lugar entre os países que mais emitem gases de efeito estufa no limiar do ano 2020.

Um ano depois, em maio de 2013, a ministra da Casa Civil, Gleisi Hoffmann, chamou de "minorias com projetos ideológicos irreais" (O GOVERNO..., 2013) os defensores dos

\footnotetext{
${ }^{5}$ Por serem declarações de chefes de Estado, importa menos o caráter da declaração (oficial ou não oficial, uma vez que as mídias digitais as colocarão em circulação) e mais que sejam discursos emitidos pelos setores do executivo, de modo que todas elas ajudam na construção de pensamentos e práticas voltados aos modos de se relacionar com a natureza.
} 
direitos constitucionais dos indígenas às suas terras. E, ainda sobre os direitos indígenas, houve silenciamento desde o governo Lula, sobre o caso Xingu e a imposição da usina Belo Monte, que pode ser acrescentada nesta construção analítica como outro dispositivo, uma vez que é expressão dos modelos de desenvolvimento nacional, imanente a conflitos históricos caracterizados pelo apagamento e silenciamento da memória de sujeitos, ao destituírem-nos de suas condições de sujeitos. A jornalista brasileira Eliane Brum chegou a afirmar que "Belo Monte só se tornou notícia negativa na maior parte da imprensa quando apareceu nas delações da Lava Jato e passou a interessar enfraquecer o PT com vistas ao impeachment de Dilma Rousseff" (BRUM, 2018). Ao assumir o segundo mandato, a presidenta Dilma manteve em aberto a promessa da demarcação das terras indígenas ( $\mathrm{TI}$ ), de Unidades de Conservação (UC) e Territórios Quilombolas.

Um quadro de impossíveis pareceu se acirrar ainda mais no mês de julho de 2017, quando Michel Temer, a pedido do governo do Ministério de Minas e Energia, assinou um decreto declarando a extinção da Reserva Nacional do Cobre e Associados (Renca) (CALIXTO, 2017). A repercussão negativa foi tão grande que houve recuo do governo e a edição de um novo decreto com texto similar foi questionada pela justiça, sendo sua medida suspensa.

Na transição Dilma-Temer, é imprescindível situar a imanência de um processo do impeachment que assinalou essa passagem. Diferente de outros contextos históricos da realidade brasileira, em que um impeachment era articulado para garantir a sucessão de poderes, o mais recente se afina num capitalismo globalitário, financeirizado e neoliberal. Daí sua diferença. Nessa condição, Rolnik (2018) pondera que dois fenômenos, neoliberalismo e o (neo)conservadorismo, até então mutuamente excludentes nas condições sócio-político-econômicas anteriores, se completam num fortalecimento mútuo, necessário à articulação do golpe de Estado mais recente: “[...] o capitalismo financeirizado precisa dessas subjetividades rudes no poder, para fazer o trabalho sujo imprescindível para a instalação de um Estado neoliberal”, nesse golpe, nosso imaginário e, portanto, as ações micropolíticas estão em jogo, uma vez que, em ato, “destroem 
todas as conquistas democráticas e republicanas, dissolvem seu imaginário e erradicam da cena seus protagonistas" (ROLNIK, 2018, p. 100). Nesse contexto, a mesma autora afirma que o governo Temer intensificou a abertura das reservas e áreas florestais para o capital externo a custos baixíssimos, sob o pretexto de crise econômica e recessão.

Esses parágrafos buscaram acentuar alguns contornos correspondentes a uma Agenda Nacional brasileira, mapeando acontecimentos mais intensos da macropolítica dos mandatos anteriores ao atual, particularmente no que se refere ao tratamento das questões ambientais, o que acaba por refletir no esgotamento micropolítico da força vital, característica do imaginário brasileiro da última década. Trata-se de um Estado que demonstrou um enfraquecimento imaginativo para lidar com os problemas ambientais, anunciados pelas ONGs e movimentos brasileiros desde a redemocratização.

Esse enfraquecimento imaginativo é menos um efeito colateral dos sistemas políticos em vigor, e mais efeito de uma crise planejada (desvio do destino ético), que se caracteriza pela "[...] expressão do esgotamento profundo dos modos de organização das lutas e mobilizações [...] uma crise de imaginação política, de medo diante das possibilidades da imaginação" (COLETIVO CENTELHA, 2019, p. 95). A relação que está em questão reside no fato de que, "em nosso modo de imaginar jaz fundamentalmente uma condição para nosso modo de fazer política. A imaginação é política, eis o que precisa ser levado em consideração" (DIDI-HUBERMAN, 2014, p. 60-61, grifos do autor).

A seção seguinte dá continuidade à cartografia dos discursos de chefes de Estado, desta vez levando em conta o governo em vigor.

\section{O regime colonial capitalístico e os enquadramentos recentes da natureza}

Ao término do mandato de Michel Temer, é Jair Messias Bolsonaro quem vence as eleições presidenciais de 2018. Dados os posicionamentos do atual presidente da república e suas declarações públicas, e à esteira de Rolnik (2018), considera-se que ele represente uma extensão dessas subjetividades rudes que dão sequência aos arcaísmos tacanhos do neoconservadorismo característico dos últimos anos. 
A controvérsia acerca de questões ambientais já se inicia antes mesmo do momento de tomada de posse, em que o abuso da força vital é ensejado na macropolítica. De acordo com os dados do Instituto Nacional de Pesquisas Espaciais, o desmatamento da Amazônia teve um agravante de 36\% apenas durante o período das eleições de 2018 (DESMATAMENTO..., 2018). No primeiro semestre de seu mandato, Bolsonaro deixa nítido quais discursos elege acerca das questões ambientais ao afirmar publicamente para a chanceler alemã, Angela Merkel, durante uma reunião do G20, que nosso país é alvo de uma "psicose ambientalista" (BOLSONARO..., 2019a). Nesta afirmação, o chefe do executivo faz um uso perverso daquilo que propõe a heterogeneidade desse movimento social, atribuindo-a a um exagero das esquerdas, ou simplesmente enquadrando discursivamente a questão ambiental na dobra colonialcapitalística. Assim, o primeiro semestre de mandato que caracterizou o acirramento do ataque à natureza na realidade brasileira com a liberação de 239 substâncias agrotóxicas em bens de consumo humano, também partidarizou a pauta ambiental (COLETIVO CENTELHA, 2019).

Também no início do mandato, em janeiro, figura o rompimento da barragem da Vale, desta vez no município de Brumadinho (MG). Ainda que o crime ambiental, tratado como "tragédia" por alguns setores da mídia, estivesse associado a uma mineradora, importa sublinhar a progressiva abstenção do Estado, representado, neste caso, pela Comissão de Minas e Energia. Após o caso de Mariana, a Câmara dos deputados se encarregou de dois projetos para aprimorar a lei que institui a Política Nacional de Segurança de Barragens, de 2010. Aprovado pela Comissão de Meio Ambiente e Integração Regional, o projeto sofre atraso na decisão da Comissão de Minas e Energia, setor composto por mais de trinta deputados financiados por mineradoras (TUROLLO JR.; ESTARQUE, 2019).

Retomando a enunciação de que nosso país é uma "psicose ambientalista", importa resgatar que, ainda em campanha, ambientalistas já alertavam sobre a possibilidade de Bolsonaro desvincular o Brasil do Acordo de Paris - evento global voltado às discussões sobre as mudanças climáticas - e, até mesmo, da ONU. Acerca dessa iminente ameaça, Erik Solheim, então chefe de meio ambiente da ONU, chegou 
anunciar publicamente: "A rejeição do Acordo de Paris é uma rejeição da ciência e do fato" [...] “É também uma promessa falsa, porque os políticos que apresentam a ação climática como um custo para a sociedade entenderam tudo errado" (DEROSA, 2018). Logo no segundo dia após sua posse, seu governo decide diminuir a força do Ministério do Meio Ambiente, transferindo seus órgãos para outras pastas, a exemplo, o Serviço Florestal Brasileiro (SFB), que se subordinaria ao Ministério da Agricultura, Pecuária e Abastecimento (BOLSONARO..., 2019b). O SFB é responsável por, dentre outras funções, apoiar a recuperação de vegetação nativa e a recomposição de áreas florestais. Além disso, o Ministério do Meio Ambiente cederia outros três órgãos - o Departamento de Recursos Hídricos, o Conselho Nacional de Recursos Hídricos e a Agência Nacional de Águas (ANA) - para o Ministério do Desenvolvimento Regional.

A conjuntura política caracterizada nessa gestão foi marcada, durante o primeiro ano de vigência, pelo enfraquecimento tático de quatro ministérios voltados à vigilância e monitoramento de áreas florestais e biodiversidade brasileira. Adensando os efeitos de um dispositivo negacionista, Bolsonaro elege Teresa Cristina, líder da bancada ruralista, para a composição do Ministério da Agricultura; a ministra Damares Alves na ocupação das pastas de preservação das populações indígenas; Ricardo Salles como ministro do Meio Ambiente e Ernesto Araújo como ministro das Relações Exteriores. Importa complementar que um ano antes de assumir tal cargo, Ricardo Salles havia sido acusado de licitações fraudulentas e improbidade administrativa no exercício da função de secretário estadual do Meio Ambiente de São Paulo (FUTURO..., 2018); e Ernesto Araújo, em longa reportagem do jornal The Guardian ${ }^{6}$, afirma que o fenômeno do aquecimento global é uma trama marxista (BRAZIL'S..., 2018), alegando que se trataria de uma tática para aumentar o poder regulador dos Estados sobre a economia, viabilizando o sufocamento do crescimento econômico. Tais lideranças contribuíram para a construção e veiculação do discurso de que as pautas ambientais são criações românticas de setores ideológicos de esquerda.

Em meados do primeiro ano de mandato, acirram as queimadas no ecossistema amazônico, o que despertou a atenção da população. As alegações do governo brasileiro

\footnotetext{
${ }^{6}$ Tal reportagens fora considerada a mais lida do ano.
} 
são variadas. Enunciam que o índice de queimadas nesse período se encontra "dentro de uma situação normal”, numa dimensão já esperada e "abaixo da média dos últimos anos" (OLIVEIRA, 2019). Além disso, o chefe do executivo afirma, posteriormente, que as mesmas queimadas podem ter sido causadas pelas próprias Organizações Não Governamentais (ONGs) localizadas no entorno da área que caracteriza a Floresta Amazônica.

É interessante retomar que para as ciências ecológicas, os biomas desenvolvem defesas autoimunes, caracterizadas pelos escudos da flora, acidentes geográficos e até mesmo existência de bacias hidrográficas que servem de escudo para a propagação das queimadas naturais (ODUM; BARRETT, 2008). Nesse sentido, a dimensão das declarações do atual presidente é desmentida publicamente logo em seguida por setores ambientalistas da sociedade brasileira (FALA..., 2019). Os mesmos setores denunciam a conjuntura política que caracterizou tal período: o Instituto Brasileiro de Meio Ambiente e Recursos Naturais (Ibama) sem presidência, dificultando ou mesmo inviabilizando suas ações de fiscalização e a recente demissão, no mesmo período, do então chefe do Instituto Nacional de Pesquisas Espaciais (Inpe) Ricardo Galvão, julgada como "alarmante", na avaliação desses setores (BARRUCHO, 2019).

As declarações apresentadas até aqui dão cabo da compreensão histórica da formação do que fora chamado, nessa investigação, de dispositivo negacionista. Característico de uma nação autoritária, que nega os avanços científicos (daí o emprego do termo negacionista), trata-se de uma rede composta por elementos discursivos e não discursivos, de caráter alienante, no sentido de ausência de preocupações com os efeitos da crise ambiental. A vontade que orienta o dispositivo negacionista, na realidade brasileira, está voltada ao retorno da acumulação primitiva, característica colonial, só que desta vez situando nosso país numa inclusão competitiva e estratégica na economia mundial que o lê como potência emergente (MORENO, 2016).

Compõe o dispositivo negacionista toda a trama cartografada até aqui: (1) a documentação de uma narrativa histórica de acumulação primitiva-colonial calcada no discurso de que os recursos naturais do Brasil são infinitos e inesgotáveis; (2) na implementação de ideais republicanos moralmente incitados por pressões externas, 
principalmente pelo mercado global, que passou a exigir uma preocupação com os recursos naturais como condição para firmar acordos econômicos, e (3) A nova dobra do capital, caracterizada pelo eclipsamento dos saberes ambientais, provenientes das ciências naturais, exatas e humanas, e das instâncias de gestão, monitoramento e vigilância, voltadas ao território brasileiro.

Uma análise passível dos efeitos depredatórios que se observou e ainda se observa no território amazônico, imanente à pobreza subjetiva que o encoraja nos últimos tempos, mediada pelo efeito do dispositivo negacionista, pode ser traçada da seguinte forma:

$\mathrm{Na}$ atual crise do capital, que se desdobrou em uma nova fase autoritária, as forças econômicas e políticas visam a exploração predatória daquilo que sobrou. Em termos imaginários, temos a reatualização do faroeste hollywoodiano. O Brasil do bang-bang só poderia ser o país da "mata virgem", inabitada, pronta para ser explorada. Nos filmes, a hostilidade da natureza (rochosa, árida, monumental) é um elemento necessário para que o herói possa mostrar sua plena força de superação representada, invariavelmente, em cenas de sanguinária brutalização. No momento atual, em que o indivíduo está mais aquebrantado do que nunca esteve, as armas e as serras elétricas adquirem, lado a lado, o estatuto de objetos de fetiche. (COLETIVO CENTELHA, 2019, p. 75-76)

$\mathrm{Na}$ atual fase do capitalismo, a natureza torna-se bode expiatório para as frustrações de diversos tipos, a maior delas, a percepção gradual de que os ideais republicanos nunca foram colocados completamente em curso. Importa destacar ainda que a força de atuação desses poderes tacanhos não se resume a um resultado final toutcourt de um imaginário incapaz de perceber esses problemas; antes, há autores que consideram que as depredações atuais em larga escala são uma reação, um contraponto da lógica do capital monopolista que, ao perceber a emergência de uma consciência ecológica - também ensejada pelos atuais aparatos tecnológicos, como a internet - reage de forma preventiva, acionada por tal dispositivo, uma vez que esta é justamente o que o atual fascismo encontra como anteparo a combater (ROLNIK, 2018; COLETIVO CENTELHA, 2019). 
A batalha fascista é pela abolição dessa necessidade de se relacionar com o que não se deixa possuir, com o que promete à vida social a possibilidade de novas formas com o que a livra dessa ilusão disciplinar de autonomia que esconde apenas um desejo inconfesso de mais dominação e distinção entre humano e animal, entre a construção do espaço social e a potência biológica da vida [...].

A natureza não é nem idílio nem estoque pronto a ser usado. Se ela é um alvo maior do fascismo, é porque novas formas de relação com a natureza implicam mutações econômicas e políticas profundas [...] A dominação dos humanos é indissociável do desejo de dominação das coisas. (COLETIVO CENTELHA, 2019, p. 78-79)

\section{Considerações finais}

O presente ensaio teórico, decorrente de um recorte analítico, buscou cartografar e, assim, visibilizar alguns dos elementos que compõem a complexa trama de um dispositivo concebido como negacionista na realidade brasileira. Buscou-se demonstrar que o caráter entreguista de nossos recursos naturais para facções exteriores não é algo recente, mas retorna, sob o imperativo de uma nova dobra do capital, designada como inconsciente colonial-capitalístico.

Sob a captura da capacidade de criação e imaginário, um dos efeitos do inconsciente colonial-capitalístico é o impedimento do destino ético populacional, colocando, no lugar de tal destino, o "sacrifício" necessário dos nossos recursos naturais como saída única da crise econômica e da atual recessão que assola o cenário brasileiro. Tal destino é facilitado pelo golpe dos imaginários utópicos orientado pela atual bancada ruralista e de uma pequena parcela da população que compõe a burguesia entreguista brasileira. A reverberação midiática dos discursos de chefes de Estado adensa a diluição da corrente ambiental alarmista, caracterizada pelos denuncismos vigorados outrora. Nesse sentido, o atual cenário é marcado por um imaginário político-ambiental no qual prevalece uma corrente técnico-administrativa que trabalha na facilitação de entreguismos dos recursos naturais. 


\section{Referências}

ACSELRAD, Henri. Ambientalização das lutas sociais: o caso do movimento por justiça ambiental. Estudos Avançados, São Paulo, v. 24, n. 68, p. 103-119, 2010.

AGAMBEN, Giorgio. Arqueologia da obra de arte: conferência de Giorgio Agamben em Scicli, Sicília, 06 ago. 2012. Disponível em:

http://flanagens.blogspot.com/2012/11/arqueologia-da-obra-de-arte.html. Acesso em: 18 maio 2016.

BARROS, Laura Pozzana de; KASTRUP, Virgínia. Cartografar é acompanhar processos. In: PASSOS, Eduardo; KASTRUP, Virgínia; ESCÓSSIA, Liliana da. Pistas do método da cartografia: pesquisa-intervenção e produção de subjetividade. Porto Alegre: Sulina, 2015. p. 52-75.

BARRUCHO, Luis. Demissão de chefe do Inpe é 'alarmante', diz diretor de centro da Nasa. BBC News, São Paulo, 07 ago. 2019. Disponível em:

https://www.bbc.com/portuguese/brasil-49256294. Acesso em: 12 jan. 2021.

BOLSONARO diz ter falado para Merkel que Brasil é alvo de 'psicose ambientalista'. G1, São Paulo, 29 jun. 2019a. Disponível em:

https:/g1.globo.com/politica/noticia/2019/06/29/bolsonaro-diz-ter-falado-para-merkel-quebrasil-e-alvo-de-psicose-ambientalista.ghtml. Acesso em: 12 jan. 2021.

BOLSONARO reorganiza ministério e "esvazia" pasta do meio ambiente. UOL, São Paulo, 02 jan. 2019b. Disponível em: https://noticias.uol.com.br/politica/ultimasnoticias/2019/01/02/bolsonaro-redistribui-ministerio-e-esvazia-pasta-do-meioambiente.htm. Acesso em: 12 jan. 2021.

BRASIL. Ministério do Meio Ambiente. Secretaria de Articulação Institucional e Cidadania Ambiental. $\mathrm{O}$ que o brasileiro pensa do meio ambiente e do consumo sustentável: pesquisa nacional de opinião: principais resultados / Ministério do Meio Ambiente, Secretaria de Articulação Institucional e Cidadania Ambiental. - Rio de Janeiro: Overview, 2012.

BRAZIL'S new foreign minister believes climate change is a Marxist plot. The Guardian, Reino Unido, 15 nov. 2018. Disponível em:

https://www.theguardian.com/world/2018/nov/15/brazil-foreign-minister-ernesto-araujoclimate-change-marxist-plot. Acesso em: 12 jan. 2021.

BRÜGGER, Paula; ABREU, Elise; CLIMACO, João Victor. Maquiagem verde: a estratégia das transnacionais versus a sustentabilidade real. In: GUIMARÃES, Leandro Belinasso; BRÜGGER, Paula; SOUZA, Suzani Cassiani; ARRUDA, VERA Lícia Vaz de (orgs.). Tecendo 
subjetividades em educação e meio ambiente. Florianópolis: NUP/CED/UFSC, 2003. p. 159170.

BRUM, Eliane. Esquerda, direita e o embargo da memória: como no Brasil atual o original e o realmente novo são silenciados para que os discursos viciados possam ser mantidos para ocupar o poder. El País, Brasil, 26 fev. 2018. Disponível em: https://brasil.elpais.com/brasil/2018/02/26/opinion/1519658924_002382.html. Acesso em: 12 jan. 2021.

CALIXTO, Bruno. O desmanche ambiental do governo Temer: para ganhar apoio no congresso, o presidente sacrifica salvaguardas ambientais do país, acelerando retrocesso dos últimos anos. Época, São Paulo, 01 set. 2017. Disponível em: https://epoca.globo.com/ciencia-e-meio-ambiente/blog-do-planeta/noticia/2017/09/odesmanche-ambiental-do-governo-temer.html. Acesso em: 12 jan. 2021.

CENTELHA, Coletivo. Ruptura. São Paulo: n-1 edições, 2019.

CRESPO, Samyra; LEITÃO, Pedro. O que o brasileiro pensa da ecologia. Rio de Janeiro: MAST/Cetem/Iser, 1993.

DANOWSKI, Déborah; VIVEIROS DE CASTRO, Eduardo. Há mundo por vir?: ensaio sobre os medos e os fins. 2. ed. Florianópolis: Ed. Desterro: Cultura e Barbárie: Instituto Socioambiental, 2017.

DEAN, Warren. A ferro e fogo: a história e a devastação da mata atlântica brasileira. São Paulo: Companhia das Letras, 1996.

DELEUZE, Gilles; GUATTARI, Félix. Mil Platôs: capitalismo e esquizofrenia 2. São Paulo: Editora 34, 2011. v.1.

DEROSA, Cristian. Bolsonaro causa pânico entre ambientalistas da ONU. Estudos Nacionais, São Paulo, 21 ago. 2018. Disponível em:

http://estudosnacionais.com/brasil/bolsonaro-causa-panico-entre-ambientalistas-da-onu/. Acesso em: 12 jan. 2021.

DESMATAMENTO cresce 36\% no período eleitoral. Observatório do clima, Brasil, 16 out. 2018. Disponível em: http://www.observatoriodoclima.eco.br/desmatamento-cresce-36no-periodo-eleitoral/. Acesso em: 12 jan. 2021.

DIDI-HUBERMAN, Georges. Sobrevivência dos vaga-lumes. Belo Horizonte: Editora UFMG, 2014.

DOMINGOS, João; MOURA, Rafael Moraes. O Estado de São Paulo, São Paulo, 05 abr. 
2012. Disponível em: http://ciencia.estadao.com.br/noticias/geral,pessoas-contrarias-ahidreletricas-na-amazonia-vivem-fantasia-diz-dilma,857484. Acesso em: 12 jan. 2021.

FALA de Bolsonaro sobre queimada na Amazônia é 'irresponsável’ e 'leviana', dizem ambientalistas. G1, São Paulo, 21 ago. 2019. Disponível em:

https://g1.globo.com/politica/noticia/2019/08/21/fala-de-bolsonaro-sobre-queimada-naamazonia-e-irresponsavel-e-leviana-dizem-ambientalistas.ghtml. Acesso em: 12 jan. 2021.

FISCHER, Rosa Maria Bueno. Foucault e a análise de discurso em educação. Cadernos de Pesquisa, n. 114. p. 197-223, novembro/2001.

FISCHER, Rosa Maria Bueno. Trabalhar com Foucault: arqueologia de uma paixão. Belo Horizonte: Autêntica Editora, 2012.

FONTES, Virgínia. David Harvey: espoliação ou expropriação? Há "lado de fora" do capital? Revista Direito e Práxis, Rio de Janeiro, v.8, n.3, p.2199-2211, 2017.

FOUCAULT, Michel. A ordem do discurso. 22. ed. São Paulo: Edições Loyola, 2012.

FOUCAULT, Michel. A arqueologia do saber. 8. ed. Rio de Janeiro: Forense Universitária, 2013.

FOUCAULT, Michel. Sobre a História da Sexualidade. In: MACHADO, Roberto (org.). Microfísica do poder. 2. ed. Rio de Janeiro: Paz e Terra, 2015. p. 363-406.

FUTURO ministro é condenado e tem direitos políticos suspensos. Exame, São Paulo, 20 dez. 2018. Disponível em: https://exame.abril.com.br/brasil/futuro-ministro-ricardo-sallese-condenado-por-improbidade-administrativa/. Acesso em: 12 jan. 2021.

GONÇALVES, CARLOS WALTER PORTO. Os (des)caminhos do meio ambiente. 14. ed. São Paulo: Contexto, 2008.

GUIMARÃES, Leandro Belinaso. O educativo nas ações, lutas e movimentos de defesa ambiental: uma história de descontinuidades. 1998. Dissertação (Mestrado em Educação) - Faculdade de Educação, Universidade Federal do Rio Grande do Sul, Porto Alegre, 1998.

HOLANDA, Sérgio Buarque de. Raízes do Brasil. 14. ed. Rio de Janeiro: José Olympio, 1981.

LATOUR, Bruno. Diante de Gaia: oito conferências sobre a natureza no Antropoceno. São Paulo: Ubu Editora, 2020. 
MARTINEZ, Paulo Henrique. História ambiental no Brasil: pesquisa e ensino. São Paulo: Cortez, 2006.

MORENO, Camila. As roupas verdes do rei: economia verde, uma nova forma de acumulação primitiva. In: DILGER, Gerhard; LANG, Miriam; PEREIRA FILHO, Jorge (orgs.). Descolonizar o imaginário: debates sobre pós-extrativismo e alternativas ao desenvolvimento. São Paulo: Fundação Rosa Luxemburgo, 2016. p. 256-295.

ODUM, Eugene; BARRETT, Gary. Fundamentos de ecologia. São Paulo: Cengage Learning, 2008.

O GOVERNO não pode e não vai concordar com minorias com projetos ideológicos irreais. O Estado de São Paulo, São Paulo, 12 mai. 2013. Disponível em: http://alias.estadao.com.br/noticias/geral,o-governo-nao-pode-e-nao-vai-concordar-comminorias-com-projetos-ideologicos-irreais-imp-,1031015. Acesso em: 12 jan. 2021.

OLIVEIRA, Cida de. Cientistas desmentem Bolsonaro: desmatamento recorde aumentou queimadas. Rede Brasil Atual, São Paulo, 16 nov. 2019. Disponível em: https://www.redebrasilatual.com.br/ambiente/2019/11/cientistas-desmentem-bolsonarodesmatamento-recorde-aumentou-queimadas/. Acesso em: 12 jan. 2021.

PASSOS, Eduardo; BARROS, Regina Benevides. A cartografia como método de pesquisaintervenção. In: PASSOS, Eduardo; KASTRUP, Virgínia; ESCÓSSIA, Liliana da. Pistas do método da cartografia: pesquisa-intervenção e produção de subjetividade. Porto Alegre: Sulina, 2015. p. 17-31.

PASSOS, Eduardo; KASTRUP, Virgínia; ESCÓSSIA, Liliana da. Pistas do método da cartografia: pesquisa-intervenção e produção de subjetividade. Porto Alegre: Sulina, 2015.

PRADO JR., Caio. Formação do Brasil contemporâneo. 11. ed. São Paulo: Brasiliense, 1971.

REIGOTA, MARCOS. Ecologia, elites e intelligentsia na américa latina: um estudo de suas representações sociais. São Paulo: Annablume, 1999.

REIGOTA, MARCOS. A floresta e a escola: por uma educação ambiental pós-moderna. 3 . ed. São Paulo: Cortez, 2002.

ROLNIK, Suely. Esferas da insurreição: notas para uma vida não cafetinada. São Paulo: N-1 edições, 2018.

SAMPAIO JUNIOR, Plínio de Arruda. Crônica de uma crise anunciada: crítica à economia política de Lula e Dilma. São Paulo: SG-Amarante, 2017. 
SCHWARCZ, Lilia Moritz. Sobre o autoritarismo brasileiro. São Paulo: Companhia das Letras, 2019.

TRIGUEIRO, André. E o “verde”, como fica? G1, São Paulo, 05 jan. 2015. Disponível em: http://g1.globo.com/natureza/blog/mundo-sustentavel/post/e-o-verde-como-fica.html. Acesso em: 12 jan. 2021.

TUROLLO JR., Reynaldo; ESTARQUE, Marina. Bancada da lama barra ações para melhorar segurança em barragens. Folha de São Paulo, São Paulo, 03 fev. 2019. Disponível em: https://www1.folha.uol.com.br/cotidiano/2019/02/bancada-da-lama-barra-acoes-paramelhorar-seguranca-embarragens.shtml?fbclid=IwARoiMbO5YMOsc3xpPMcotx5aMhNIMvM9DNUZk4fcMsqaCO1 -V2HECbSzCRQ. Acesso em: 12 jan. 2021.

Recebido em: 01/05/2020 Aprovado em: 22/11/2020

Universidade do Estado de Santa Catarina - UDESC Centro de Ciências Humanas e da Educação - FAED

PerCursos

Volume 21 - Número 47 - Ano 2020 revistapercursos@gmail.com 